\title{
Technical Note: The impact of spatial scale in bias correction of climate model output for hydrologic impact studies
}

\author{
E. P. Maurer ${ }^{1}$, D. L. Ficklin ${ }^{2}$, and W. Wang ${ }^{3}$ \\ ${ }^{1}$ Santa Clara University, Civil Engineering Department, Santa Clara, CA 95053-0563, USA \\ ${ }^{2}$ Indiana University, Department of Geography, Bloomington, IN 47405, USA \\ ${ }^{3}$ California State University at Monterey Bay, Department of Science and Environmental Policy and \\ NASA Ames Research Center, Moffett Field, CA 94035, USA \\ Correspondence to: E. P. Maurer (emaurer@engr.scu.edu)
}

Received: 21 July 2015 - Published in Hydrol. Earth Syst. Sci. Discuss.: 23 October 2015

Revised: 15 January 2016 - Accepted: 26 January 2016 - Published: 12 February 2016

\begin{abstract}
Statistical downscaling is a commonly used technique for translating large-scale climate model output to a scale appropriate for assessing impacts. To ensure downscaled meteorology can be used in climate impact studies, downscaling must correct biases in the large-scale signal. A simple and generally effective method for accommodating systematic biases in large-scale model output is quantile mapping, which has been applied to many variables and shown to reduce biases on average, even in the presence of non-stationarity. Quantile-mapping bias correction has been applied at spatial scales ranging from hundreds of kilometers to individual points, such as weather station locations. Since water resources and other models used to simulate climate impacts are sensitive to biases in input meteorology, there is a motivation to apply bias correction at a scale fine enough that the downscaled data closely resemble historically observed data, though past work has identified undesirable consequences to applying quantile mapping at too fine a scale. This study explores the role of the spatial scale at which the quantile-mapping bias correction is applied, in the context of estimating high and low daily streamflows across the western United States. We vary the spatial scale at which quantilemapping bias correction is performed from $2^{\circ}(\sim 200 \mathrm{~km})$ to $1 / 8^{\circ}(\sim 12 \mathrm{~km})$ within a statistical downscaling procedure, and use the downscaled daily precipitation and temperature to drive a hydrology model. We find that little additional benefit is obtained, and some skill is degraded, when using quantile mapping at scales finer than approximately $0.5^{\circ}$ $(\sim 50 \mathrm{~km})$. This can provide guidance to those applying the
\end{abstract}

quantile-mapping bias correction method for hydrologic impacts analysis.

\section{Introduction}

Climate modeling is an imperfect science, with uncertainties in simulated land-surface climate that vary in space and with the forecast time horizon (Hawkins and Sutton, 2009, 2011). This presents a challenge when projecting climate change impacts at a local and regional scale. The most recent coordinated global climate model (GCM) experiments conducted as part of the fifth Coupled Model Intercomparison Project (CMIP5; Taylor et al., 2012) have been used to simulate historic and future climate. These CMIP5 runs have demonstrated improvements over earlier generations of models, both in the representation of physical processes and the simulated fields (Flato et al., 2013; Watterson et al., 2014). While improved skill over the United States has been found for both mean and variability of climate (Sheffield et al., 2013a, b), biases remain that must be accommodated for projecting future impacts, e.g., on streamflow characteristics (Wood et al., 2004).

In this study we focus on a common method used for bias correction, namely, quantile mapping. Quantile mapping is effective at removing some climate model biases, is relatively simple to apply, and has been incorporated into many statistical downscaling schemes used for local and regional impacts analysis (Li et al., 2010; Maraun et al., 2010; Panofsky and Brier, 1968; Piani et al., 2010; Themeß1 et al., 
2011). While quantile-mapping bias correction does inherently assume that the biases exhibited by a climate model remain constant in future projections, there is some indication that this is not an unreasonable assumption (Maraun, 2012; Maurer et al., 2013), especially where biases are driven by persistent climate model characteristics, such as inadequate representation of topography. Other discrepancies between historic climate model simulations and observations, especially due to internal natural variability (for example, El Niño events simulated by a freely evolving GCM not coinciding with observations), are not necessarily model biases (Eden et al., 2012), but are corrected nonetheless by quantile mapping, which is blind to the source of the bias. For this reason, the training (or calibration) period for the bias correction should be long enough (typically 10-30 years) so that internal variability is not a dominant source of bias between the climate model and observations.

In statistical downscaling approaches that incorporate a quantile-mapping bias correction, large-scale climate model output is typically first interpolated onto a regular grid and then bias corrected using quantile mapping with a gridded observational data set at the same spatial resolution (Maurer et al., 2010b; Thrasher et al., 2012). This was originally developed as a method of convenience to place the climate models, which operate natively at many different spatial resolutions, onto a single grid to enable straightforward intercomparisons. Using a common grid for all climate models also ensures that the bias corrected output from each (regridded) climate model, for the time period on which the quantile mapping is calibrated, is statistically identical.

The scale at which global climate models were bias corrected for the archive of downscaled climate model output (from the prior CMIP3 experiment; Meehl et al., 2007), described by Maurer et al. (2007) for the conterminous United States, was $2^{\circ}$ (latitude and longitude) or roughly $200 \mathrm{~km}$, approximately corresponding to the finest spatial resolution of the participating climate models. Using similar logic, for the expansion of the archive with downscaled CMIP5 climate model output (Maurer et al., 2014), which included climate models operating at higher spatial resolutions, the resolution at which bias correction was performed was refined to $1^{\circ}$. Of course, when further spatial disaggregation to finer scale is performed after the bias correction, the correspondence between bias corrected climate model output and observations at the fine scale degrades, since fine-scale climate information is not incorporated in the bias correction.

To ensure closer correspondence between the final downscaled product and observations, a temptation is to apply quantile-mapping bias correction at a finer scale, which in its limit would be applied at the scale of observations (either at the original grid scale, or even to point observation stations). This approach has been applied to climate model output at many spatial scales: for example, Wood et al. (2004) applied it at a $2^{\circ}(\sim 200 \mathrm{~km})$ spatial scale, Li et al. (2010) used quantile mapping at $1^{\circ}(\sim 100 \mathrm{~km})$, Hwang and Graham (2013) and Tian et al. (2014) applied it at $1 / 8^{\circ}(\sim 12 \mathrm{~km})$, Abatzaglou and Brown (2012) applied quantile mapping at $1 / 12^{\circ}$ $(\sim 8 \mathrm{~km})$, and Tryhorn and DeGaetano (2011) used quantile mapping to bias correct to point observations of precipitation and temperature.

One problem with applying quantile mapping at fine scales has been identified by Maraun (2013, 2014). In summary, the adjustment by quantile mapping inappropriately applies a deterministic variance correction, implicitly assuming that any unexplained variance at the fine spatial scale can be accommodated by rescaling the variance from the large scale. In other words, a climate model grid scale precipitation value (representing average precipitation over approximately $10000 \mathrm{~km}^{2}$ ) would be used to adjust the precipitation (probability distribution) at a much smaller scale (for example, $100 \mathrm{~km}^{2}$ ). In essence, this assumes the unexplained variability of fine-scale precipitation can be described with a deterministic function of large-scale precipitation variability. Since variability at the coarse-scale (due to synoptic circulation, for example) and fine-scale (due to local topographic features, land-atmosphere interactions, etc.) have distinct sources, application of quantile mapping to simultaneously include spatial downscaling is arguably inappropriate. For example, Maraun (2013) highlighted an example where a high large-scale precipitation value is translated by quantile mapping to high values at all points within the large-scale grid box, producing an erroneously large and uniform extent of an extreme event; fine-scale variability among the points is not replicated by the deterministic transformation of quantile mapping. It should be noted that where downscaling to point observations is required, others have proposed alternative approaches that expand beyond the quantile mapping used in this study (e.g., Haerter et al., 2015).

Another issue with fine-scale application of quantile mapping of precipitation has been related to spatial correlation of storm events (Bárdossy and Pegram, 2012). They found quantile-mapping bias correction of precipitation at $25 \mathrm{~km}$ decreased spatial correlation with observations, and hence underestimated areal precipitation at larger scales. This could have potential negative effects on flood estimates for large river basins, and Bárdossy and Pegram (2012) proposed a re-correlation technique to restore some of the observed spatial structure of precipitation events. A further consideration, when applying quantile mapping to future precipitation projections, is that the relationship between the spatial scale of fine- and coarse-scale precipitation may change in ways that could affect extreme runoff projections (Li et al., 2015).

In addition to those noted above, there are other known shortcomings of quantile mapping, some of which have been accommodated by modifying or augmenting quantile mapping or by developing alternative statistical procedures. For example, where it is desired to maintain a joint distribution of multiple variables through bias correction, as opposed to individual variable downscaling as used here, joint downscaling methods have been developed (Abatzoglou and Brown, 


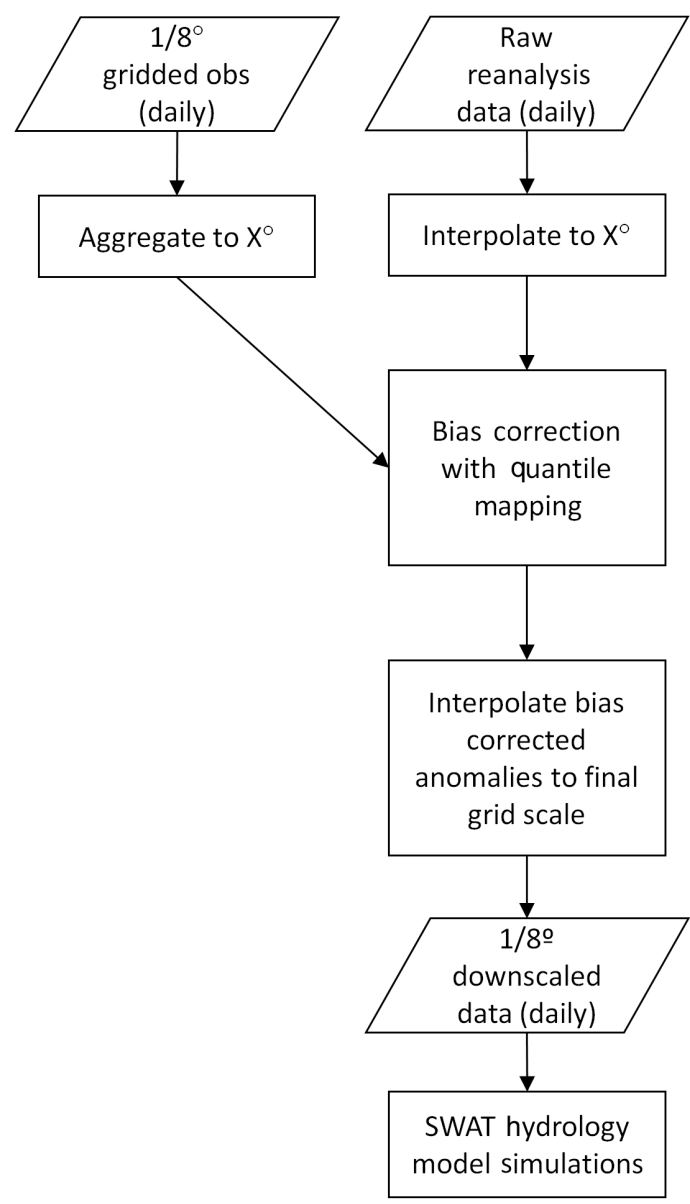

Figure 1. Schematic of bias correction-spatial disaggregation process used in this experiment. Values for $X$ vary from $2^{\circ}$ (latitudelongitude) to $0.125^{\circ}$ as described in the text.

2012; Mehrotra and Sharma, 2015; Zhang and Georgakakos, 2012). The probability transformations in quantile mapping are incapable of correcting for GCM biases in low-frequency variability, and autoregressive and spectral transformations have been developed to accommodate these biases where important (Mehrotra and Sharma, 2012; Pierce et al., 2015). While we recognize the deficiencies in quantile mapping, as discussed for statistical bias correction in general by Ehret et al. (2012), and there is the promise of recent advances in bias correction, it remains that quantile mapping is widely used and generally effective at removing biases (Gudmundsson et al., 2012), even in the presence of some non-stationarity (Lafon et al., 2012; Maurer et al., 2013; Teutschbein and Seibert, 2013). Our aim in this study is not to advocate for a specific downscaling method, but to understand a specific aspect of this widely used method.

The question we aim to address in this study is whether there is a practical limit to spatial scale that should be considered when applying quantile-mapping bias correction in statistical downscaling in the context of projecting hydro- logic impacts. Past work on western US hydrology has found negligible predictive skill, and in some locations a degradation, when bias correction is performed at a fine spatial scale (Maurer et al., 2010b).

To assess this, we begin with large-scale climate data (approximately $200 \mathrm{~km}$ spatial scale) and perform a quantilemapping bias correction at a variety of spatial scales, as part of a statistical downscaling approach, to obtain fine-scale gridded daily precipitation and temperature values. These downscaled meteorological data are used to drive a hydrological model over the western United States to simulate streamflow at sites where streamflow is observed, representing drainage areas from approximately 100 to $600000 \mathrm{~km}^{2}$. Skill is assessed by comparing the streamflow simulated by the downscaled meteorology and the streamflow from a simulation using observed meteorology. Ultimately, we aim to determine whether the improved correspondence between downscaled large-scale climate and fine-scale observed meteorology comes with a cost of degraded skill outside of the training period used for bias correction. This can be helpful for guiding future downscaling efforts for assessing the impacts of climate change on water resources.

\section{Data and methods}

The quantile-mapping bias correction is performed as a first step in the bias correction-spatial disaggregation (BCSD; Wood et al., 2004) technique. A schematic of the procedure is shown in Fig. 1. Observations of gridded daily precipitation and temperature (Livneh et al., 2013) are available at a $1 / 16^{\circ}$ spatial resolution; to reduce the computational load they are aggregated to a $1 / 8^{\circ}\left(0.125^{\circ}\right)$ resolution for this experiment. The Livneh et al. data use approximately 20000 sites with daily meteorological records to define their field. These $1 / 8^{\circ}$ gridded observations are then aggregated to different spatial resolutions to match the interpolated large-scale daily data $\left(X^{\circ}\right.$ in Fig. 1)

A quantile-mapping approach is used to bias correct the large-scale data, in which empirical cumulative distribution functions (CDFs) are developed for both the aggregated observations and the interpolated large-scale data for a calibration period. The quantile for each large-scale value is then determined using its CDF, and the value is transformed to the observed value at the same quantile. This transfer function, following Li et al. (2010), can be written as

$x_{\text {model-adjusted }}=F_{\text {obs }}^{-1}\left(F_{\text {model }}\left(x_{\text {model }}\right)\right)$,

where $F$ is the $\mathrm{CDF}$ for the calibration period, $x$ is a daily value of precipitation or temperature, with the $\mathrm{CDF}$, at each $X^{\circ}$ grid cell, developed for a moving window of \pm 15 days from the day pertaining to $x$. The subscripts indicate largescale model data or observations (obs). After the quantilemapping bias correction, precipitation and temperature values are expressed as anomalies relative to the climatolog- 
ical mean for the moving window, using a difference for temperature and a fraction for precipitation. These anomalies are interpolated from the large scale to the final $1 / 8^{\circ}$ grid and applied to climatological values to obtain final daily downscaled data. Details of the quantile mapping and BCSD method as applied here are available elsewhere (Maurer et al., 2010b; Thrasher et al., 2012).

The large-scale climate data we use are daily precipitation and maximum and minimum surface air temperature from the National Centers for Environmental Prediction and the National Center of Atmospheric Research (NCEP/NCAR) reanalysis (Kalnay et al., 1996) as a surrogate for a GCM. Because NCEP/NCAR reanalysis ingests some atmospheric observations (though, importantly, not precipitation) in its production, it exhibits a higher skill than possible with GCMs (Reichler and Kim, 2008). While it arguably represents a best possible simulation capability of a GCM, it still can exhibit substantial regional biases, especially in precipitation (Maurer et al., 2001; Widmann and Bretherton, 2000; Wilby et al., 2000). The assimilation of some observed atmospheric states means that NCEP/NCAR reanalysis can be expected to have some correspondence to observed events, which would be impossible with a freely evolving GCM. These characteristics make the use of reanalysis data for evaluating bias correction and downscaling procedures common practice (e.g., Huth, 2002; Schmidli et al., 2006; Vrac et al., 2007).

Reanalysis data are available on a T62 Gaussian grid (approximately $1.9^{\circ}$ square), a resolution comparable to current GCMs. Daily reanalysis precipitation, maximum and minimum temperature are bilinearly interpolated onto regular grids of varying spatial resolutions (designated as $X$ in Fig. 1) prior to bias correction: 2.0, 1.0, 0.5, 0.25, $0.125^{\circ}$. The gridded observations are aggregated to the same spatial scale as the interpolated reanalysis data and the bias correction is then performed at that scale. The period 1960-1989 is used to calibrate or train the bias correction, and 1990-2011 is used to validate the downscaled data. This analysis was conducted over the conterminous United States for all of the spatial resolutions except the $0.125^{\circ}$ experiment, which used a smaller domain over the western United States for computational reasons.

Both the downscaled meteorology and the gridded observations were used to drive three Soil Water and Assessment Tool (SWAT; Arnold et al., 1998) hydrologic models over the western United States (for the Columbia River basin, Sierra Nevada, and Upper Colorado River basin). SWAT simulates the entire hydrologic cycle, including surface runoff, snowmelt, lateral soil flow, evapotranspiration, infiltration, deep percolation, and groundwater return flows, at the subbasin scale. The subbasins delineated for these SWAT models have average areas ranging from $246 \mathrm{~km}^{2}$ (for the Colorado basin) to $191 \mathrm{~km}^{2}$ (for the Sierra), comparable to that of the $1 / 8^{\circ}$ gridded observational data (approximately $140 \mathrm{~km}^{2}$ per grid cell). Each SWAT subbasin uses the meteorology from the nearest $1 / 8^{\circ}$ grid cell. Calibration was performed at 185 different streamflow sites, shown in Fig. 2, where naturalized or unimpaired streamflow observations were available. All SWAT models were calibrated and validated, at the 185 sites, during the 1950-2005 time period, though because observations were not complete at all sites some gauges did not encompass the entire period. The contributing drainage areas of these sites varied from approximately 100 to $600000 \mathrm{~km}^{2}$, and these calibration sites are the locations where streamflows are analyzed for this study. The parameterization, calibration, and validation of the SWAT model used in this study for three major western US river basins are described in detail in other references (Ficklin et al., 2012, 2013, 2014).

The streamflow metrics applied in this study are the annual 3-day peak flow and 7-day low flow at each site, and only the validation period of 1990-2011 is used. These metrics aim to quantify extreme high and low values without applying a theoretical distribution, as would be required to estimate more rare events from the relatively short validation period. The 3-day peak flow is a widely used measure for flood planning purposes (e.g., Das et al., 2013) and the 7-day low flow is frequently used for characterizing water quality and ecosystem impacts (WMO, 2009). The annual extreme streamflow values are analyzed using the non-parametric Mann-Whitney $U$ test (Haan, 2002) for equality of medians to determine the significance of the difference between flows driven by observations and those driven by downscaled reanalysis data.

\section{Results and discussion}

As an overview of the larger domain of the study, Fig. 3 shows the biases in mean annual (daily) precipitation for each of the experiments. Figure 3 demonstrates that, as will always be the case due to natural variability, the biases between climate model output (or reanalyses) and observations will be different for different time periods. It is also evident, for the precipitation statistic depicted, that the difference in bias between the two periods is much smaller than the bias itself, explaining why bias correction generally does improve skill, especially given the role of topography in precipitation formation and the lack of detailed topographic representation in the large-scale reanalysis data (e.g., Maurer et al., 2013). Comparing the change in bias between the two periods at different spatial scales (each row of the right column), Fig. 3 shows that the non-stationarity has the same overall pattern at all scales, but at finer scales there is greater spatial variability, with some isolated grid cells showing greater non-stationarity at fine scales. Figure 3 shows the mountainous regions to have higher biases (and greater values for non-stationarity), which may be expected given greater local complexity of the terrain and thus more heterogeneity in the local precipitation that the bias correction is attempting to correct. However, the apparent higher non-stationarity in mountainous areas is also partially due to the greater precipitation at high elevations. Expressing bias as a relative 


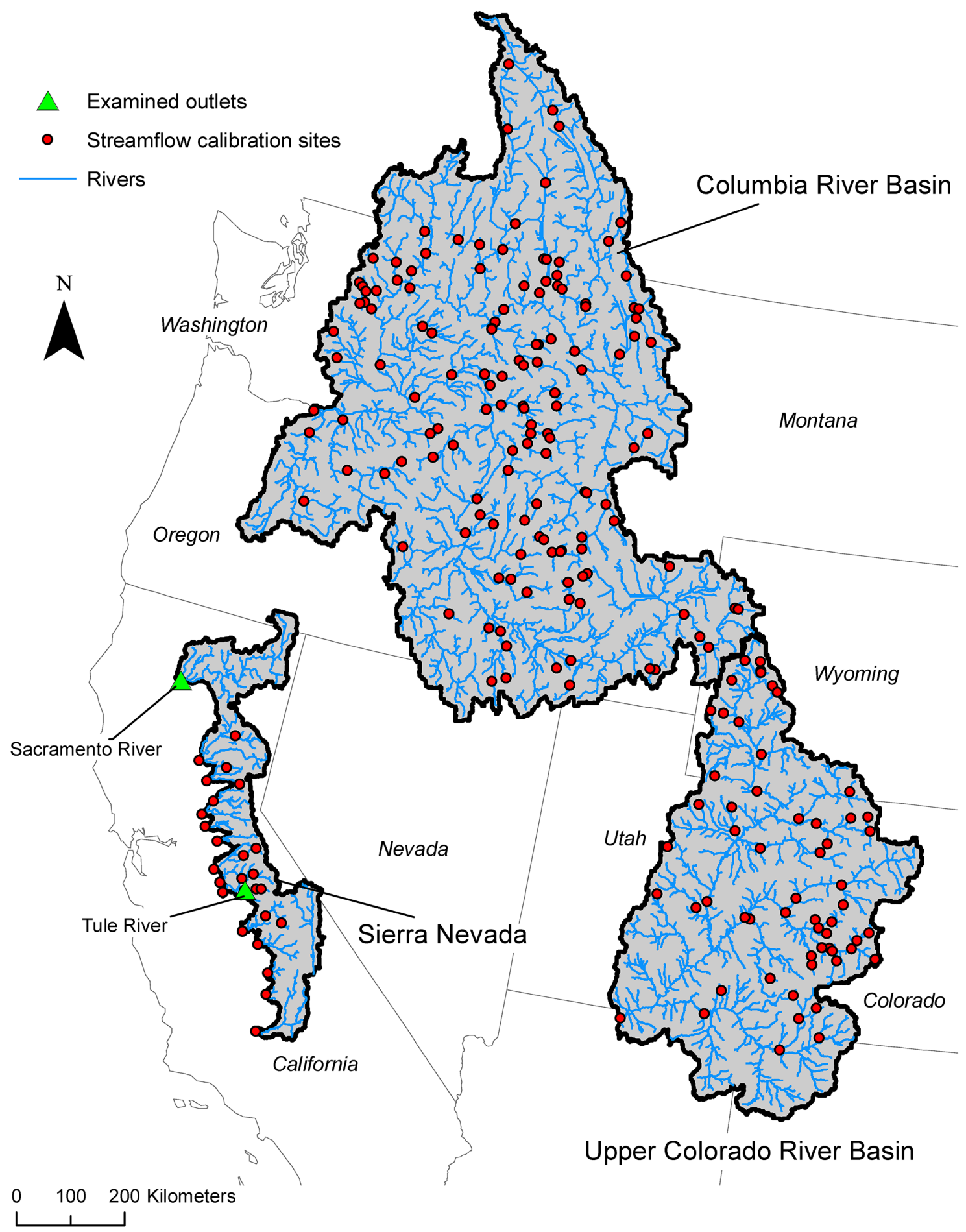

Figure 2. Streamflow locations used in this study. 

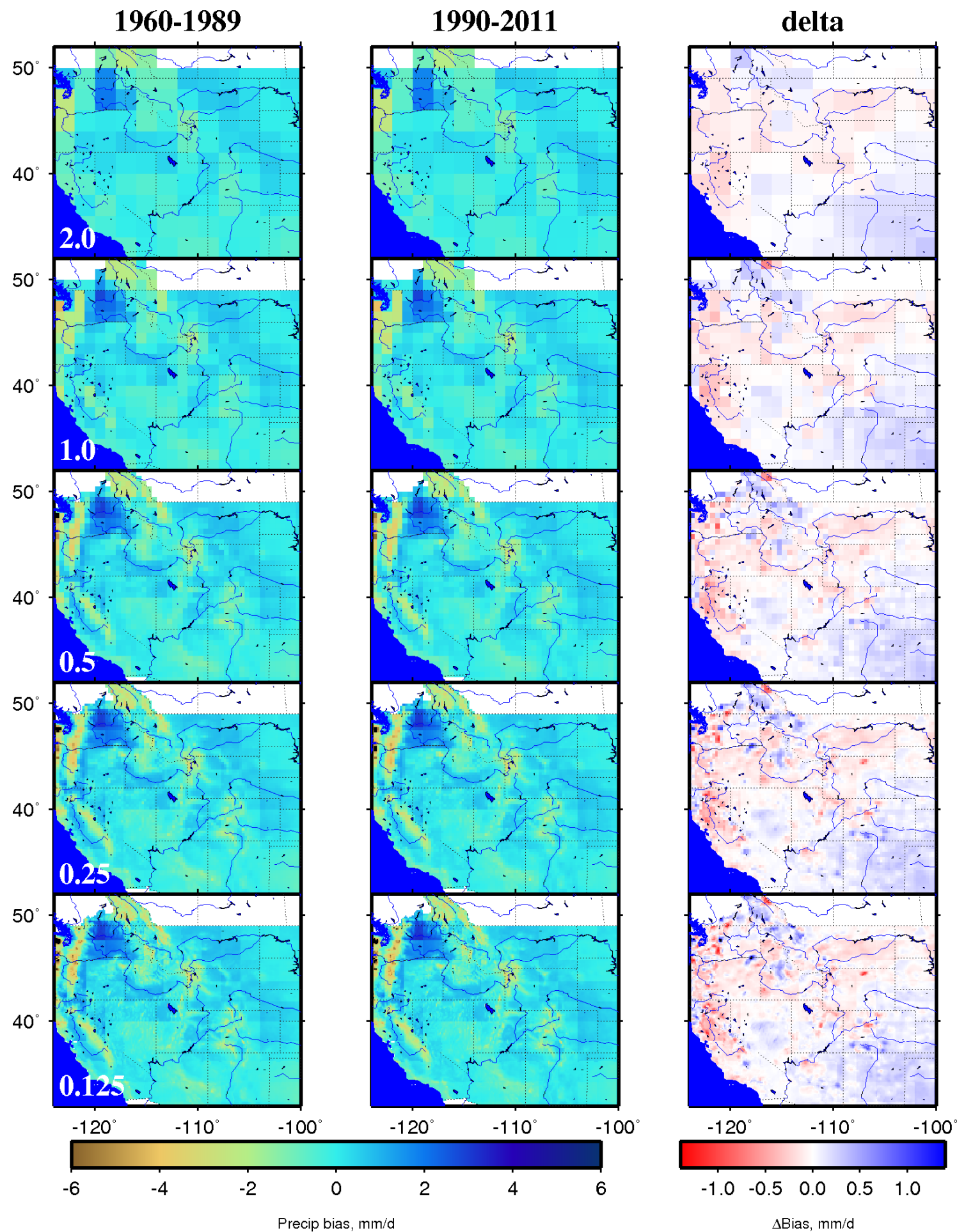

Figure 3. Mean precipitation bias, measured as the difference between reanalysis and observations for the calibration (1960-1989) and validation (1990-2011) periods, and the difference in bias between the two periods. Reanalysis data are interpolated and observations aggregated to the spatial resolution indicated in the left column. 

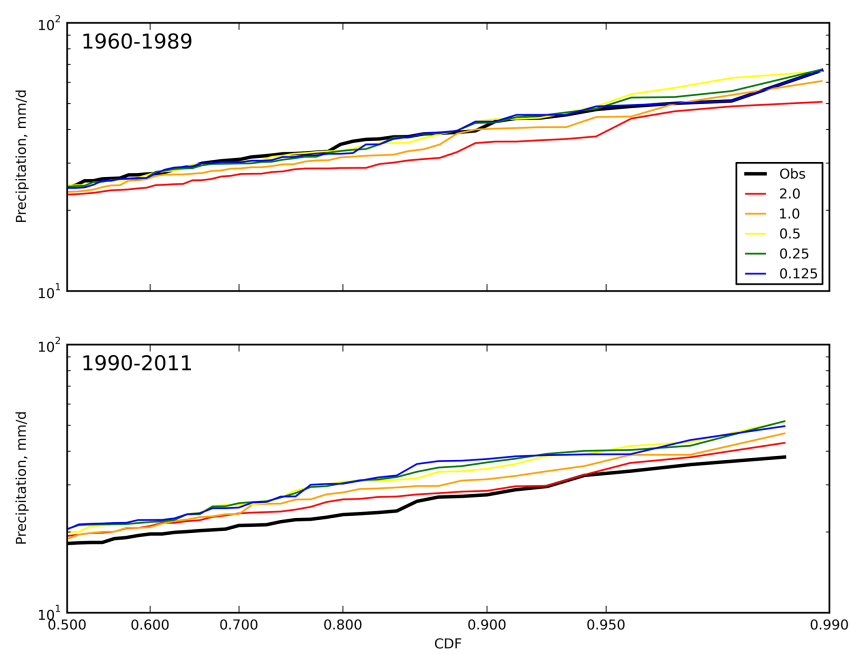

Figure 4. Cumulative distribution function plots (for quantiles 0.50.99 ) of bias-corrected and spatially disaggregated daily precipitation for a single grid cell at latitude 45 , longitude -116 . Spatial resolution in degrees at which the bias correction is performed is indicated in the legend. "Obs" is the CDF for the observations at $1 / 8^{\circ}$ spatial resolution.

change in bias (by dividing the bias at each grid cell by the mean observed precipitation) shows higher non-stationarity, and the amplification at some locations, to occur not only in some mountainous areas but also more broadly over much of the domain, including some prominent valleys such as California's Central Valley. The mechanisms driving the spatial variability in bias non-stationarity, and its amplification when bias correcting at finer scales, is reserved for future research. These locations where non-stationarity is amplified could be a concern for cases where bias correction is applied at fine scales, as there would be increased risk that the bias correction could ultimately degrade the skill of the climate data. A similar plot to Fig. 3, but for annual maximum precipitation, showed comparable patterns and characteristics.

To illustrate how these characteristics vary at different scales, Fig. 4 shows the impact of bias correction at different spatial scales on the downscaled precipitation at a single grid cell. Only quantiles above 0.5 (50\% non-exceedance probability) are shown to focus on the higher precipitation values. While not used for quantitative analysis at this point, Fig. 4 does demonstrate some of the impacts of performing bias correction at different scales. As would be expected, interpolating the reanalysis data to the $1 / 8^{\circ}$ spatial scale prior to bias correction (reversing the process to the SDBC technique) provides the best fit to the observations for the calibration period. However, Fig. 4 shows that this also provides the worst correspondence to the $\mathrm{CDF}$ for observations at most quantiles during the validation period, illustrating that the instability of the biases at the finer scale may be a disincentive to performing the bias correction at too fine a scale. In other words, the CDF of precipitation at the finest resolution used
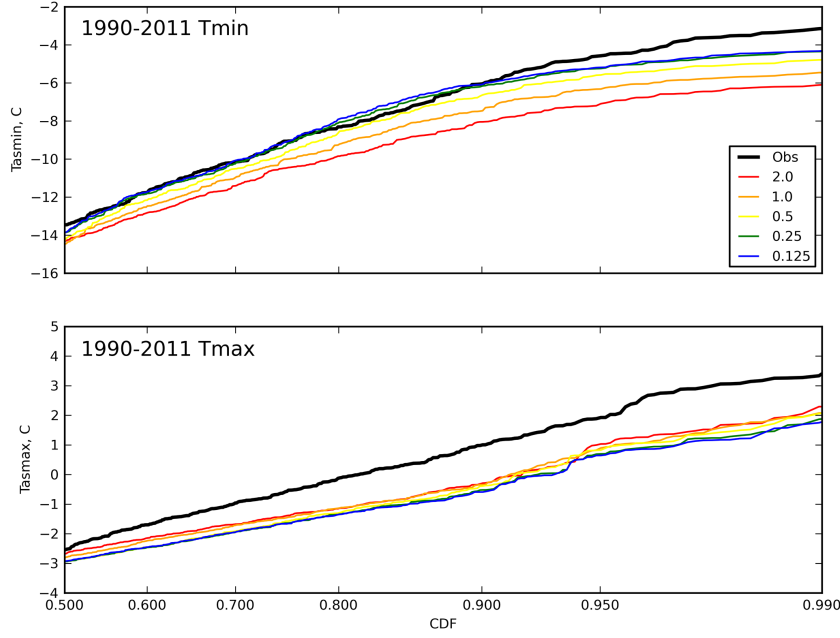

Figure 5. Similar to Fig. 4, but for the validation period for minimum daily temperature (upper panel) and maximum daily temperature (lower panel).

here $\left(1 / 8^{\circ}\right)$ is likely not as stationary between two time periods as a CDF at a larger spatial scale would be. It should be noted that this stark of an example will not exist at every grid cell. Eden et al. (2012) suggest that model errors due to unrepresented topographic effects on precipitation or inadequate climate model parameterization are most successfully corrected by quantile mapping, so where other small-scale variability is less important there may be more successful removal of biases using quantile mapping at finer scales.

While precipitation is the primary variable affecting streamflow, in many parts of the western US temperature has a large impact in the hydrologic response to a changing climate, due to its effect on the nature of precipitation and the rate of snowmelt (Barnett et al., 2008). Figure 5 is similar to the lower panel of Fig. 4, showing the CDFs (for quantiles above 0.5 ) for the validation period for maximum and minimum daily temperatures for the same location. At this one sample point performing the bias correction of minimum temperatures at the finer spatial resolution provides the closest correspondence to the observations at these higher quantiles, with progressively worse results with bias correction at the larger scales. For maximum temperature, the results are inverted, with bias correction at the largest scale appearing slightly closer to observations, though all resolutions are clustered together. This shows how the results can vary across quantiles, for different variables, as well as with location (shown in Fig. 3).

Since the interest of this study is on the ultimate hydrologic impacts of these differences in downscaling approaches, not the precipitation or temperature, we turn the focus to how streamflow skill is affected by bias correction at different spatial scales. Figure 6 shows the distribution of daily streamflows simulated by the SWAT model for the Tule River basin (see Fig. 2), which has a contributing drainage 


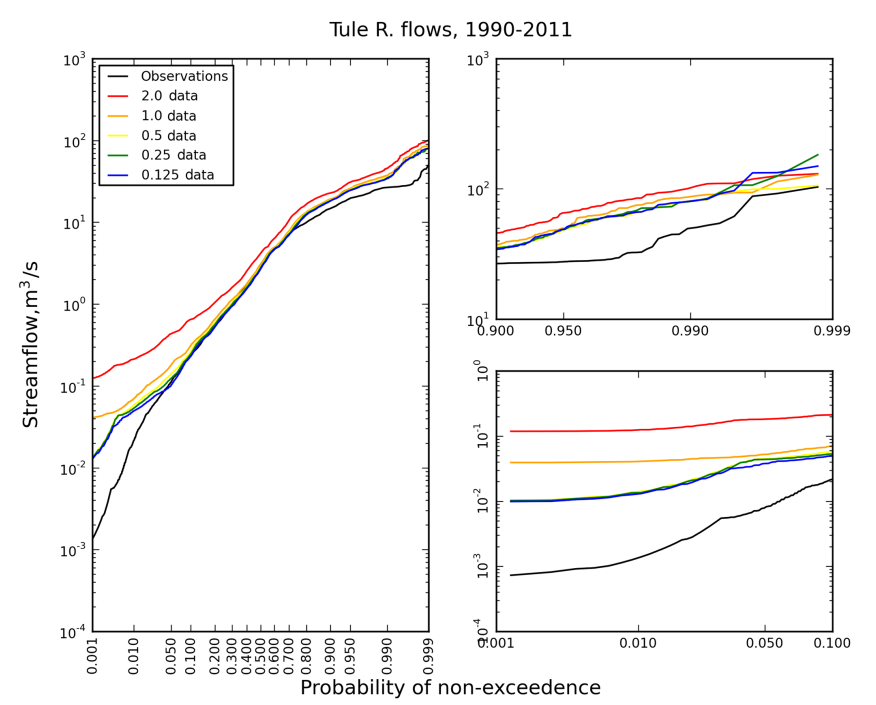

Figure 6. Cumulative distribution function for the daily streamflows at the Tule River gauge. The full CDF is in left panel, upper right panel expands the highest $10 \%$ of flows, and the lower right highlights the $10 \%$ lowest flows.

area of $1015 \mathrm{~km}^{2}$, approximately equivalent to $1 / 3^{\circ}$ spatial resolution. The simulated flows are overpredicted at all quantiles for this location, with the departure more visible at the high and low extremes. The upper right panel of Fig. 6 shows that for the highest $10 \%$ of daily flows performing bias correction at the coarsest $2^{\circ}$ resolution results produces less correspondence with observations than bias correcting at finer resolutions, while other spatial resolutions are more tightly clustered. Only the most extreme flows (the highest 1\%) show a change in the spatial resolution with the higher skill, where the $0.5^{\circ}$ experiment more closely resembles the observed flow probabilities. The lower right panel in Fig. 6 plots the lower $10 \%$ of streamflows, showing the $2^{\circ}$ and $1^{\circ}$ experiments overpredicting the observed flow frequency more than those at $0.5,0.25$, and $0.125^{\circ}$, which are all nearly coincident.

As a point of contrast, Fig. 7 shows the same information as Fig. 6 but for a larger basin, the Sacramento River (see Fig. 2), which has a drainage area of $18835 \mathrm{~km}^{2}$, approximately equivalent to a $1.4^{\circ}$ spatial scale. Similar to the smaller Tule River site, the experiment with the bias correction performed at $2^{\circ}$ performed worst overall, especially evident at high flows (shown in the upper right panel of Fig. 7). The $1^{\circ}$ bias correction produced the best correspondence with observed flows at the low extremes (lower right panel), with the coarse $2^{\circ}$ overpredicting daily low-flow magnitudes and the finer scale 0.25 and $0.125^{\circ}$ bias correction underpredicting low flows to the greatest degree. As with Fig. 6, Fig. 7 shows worse performance of bias correction in many cases at the high and low extremes compared to the center of the distribution, as would be expected with fewer observa-

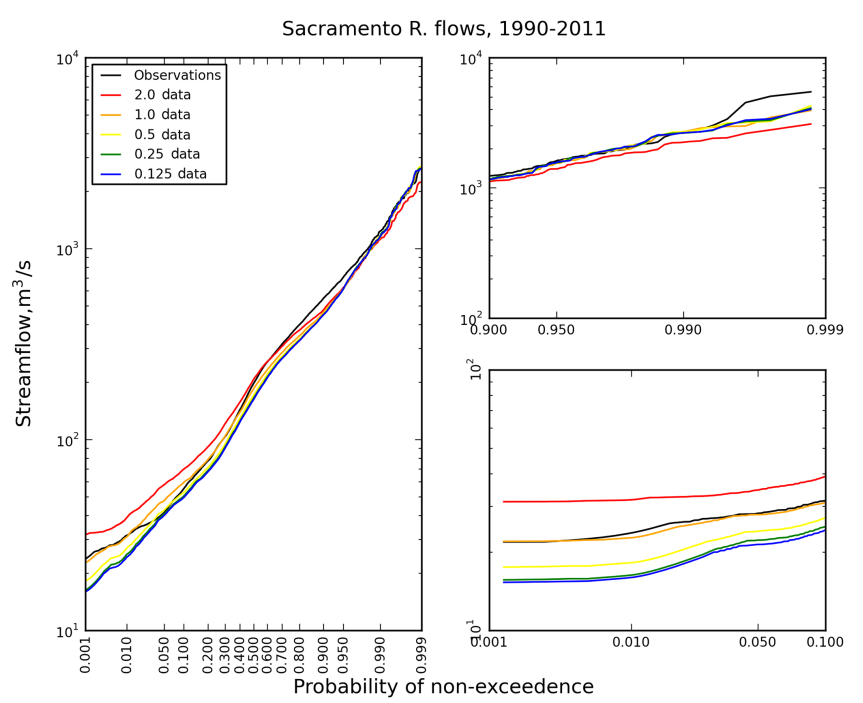

Figure 7. Similar to Fig. 6, but for the Sacramento River stream gauge site.

tions for defining the driving precipitation and temperature CDFs in the relatively short calibration period. Thus, while quantile mapping generally reduces the biases compared to using raw GCM output, significant biases may remain, especially at the tails of the distributions. If streamflows produced using bias corrected and downscaled GCM output are to be used for analysis of extreme events, it may be desirable to use a further bias correction (such as quantile mapping of simulated streamflows to match observed streamflows), as has been done for water resources system operations and seasonal forecasting (Snover et al., 2003; Yuan and Wood, 2012) to ensure downscaled streamflows are comparable to observations at all quantiles.

Figures 6 and 7 raise the question of whether a limit exists for the scale at which bias correction should be performed, or whether, for improved skill of simulated daily streamflows there may be a correspondence between the scale at which bias correction is done and the drainage area of the streamflow site. To investigate this, Fig. 8 shows the results of the Mann-Whitney $U$ test for all basins for 3-day maximum flows. Since the null hypothesis is that the streamflows produced by driving the SWAT model with observations are statistically indistinguishable from simulated flows using downscaled reanalysis data, a small $p$ value indicates that the two can be confidently claimed to be different. There is no clear relationship between drainage areas and the skill (defined by the $p$ values) for the different experiments. One observation based on Fig. 8 is that there are more basins with $p$ values $<0.1$ (indicating low correspondence between observation- and reanalysis-driven streamflows) when bias correction is done at $2.0^{\circ}$ than for the other experiments. Regardless of the spatial scale of the bias correction, there are always some small basins $\left(<1000 \mathrm{~km}^{2}\right)$ where the correspon- 
Table 1. Summary of the percentage of streamflow sites with $p<0.1$ and $p<0.05$ (shown in Figs. 8 and 9).

\begin{tabular}{lrrrr}
\hline & \multicolumn{2}{c}{ Percent of sites with $p<0.1$} & \multicolumn{2}{c}{ Percent of sites with $p<0.05$} \\
\cline { 2 - 5 } $\begin{array}{l}\text { Spatial resolution used } \\
\text { for bias correction }\end{array}$ & $\begin{array}{r}\text { 3-day maximum } \\
\text { flows }\end{array}$ & $\begin{array}{r}\text { 7-day minimum } \\
\text { flows }\end{array}$ & $\begin{array}{r}\text { 3-day maximum } \\
\text { flows }\end{array}$ & $\begin{array}{r}\text { 7-day minimum } \\
\text { flows }\end{array}$ \\
\hline $2.0^{\circ}$ & 22.0 & 30.6 & 17.7 & 23.7 \\
$1.0^{\circ}$ & 12.4 & 19.9 & 5.9 & 14.5 \\
$0.5^{\circ}$ & 6.5 & 13.5 & 4.3 & 8.1 \\
$0.25^{\circ}$ & 9.1 & 17.2 & 4.3 & 10.8 \\
$0.125^{\circ}$ & 9.1 & 18.3 & 5.4 & 15.1 \\
\hline
\end{tabular}

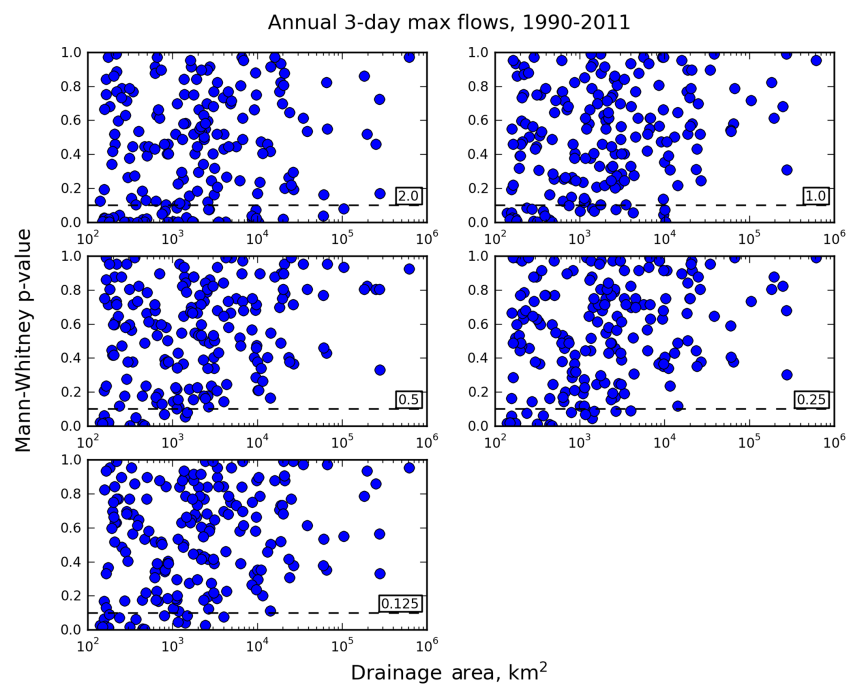

Figure 8. $P$ values from the Mann-Whitney $U$ test vs. the drainage area for each of the streamflow sites in Fig. 2. The dashed horizontal line at $p=0.1$ is shown for reference; $p$ values less than this are indicative of poor correspondence between observation- and reanalysis-driven streamflows.

dence between observation- and reanalysis-driven streamflows is weak. Bias correction at scales smaller than $0.5^{\circ}$ appears to offer little improvement in skill, and may even result in more streamflow sites having poor skill $(p<0.1)$. This apparent $0.5^{\circ}$ limit may reflect both the finest scale at which the large-scale reanalysis variance in meteorology can be effectively rescaled (Maraun, 2013) and the degradation of larger-scale spatial structure of driving meteorology (Bárdossy and Pegram, 2012) when applying quantile-mapping bias correction at finer spatial scales.

Figure 9 shows the relationship between the MannWhitney $p$ value and the drainage area for each of the streamflow sites for 7-day minimum flows. Similar to the 3-day peak flows, there is a weak correspondence between the scale at which the bias correction is performed and the skill for basins of different drainage areas. As with 3-day peak flows, bias correction at $0.5^{\circ}$ appears as a point at which finer scale bias correction does not offer any improvement, and may in-

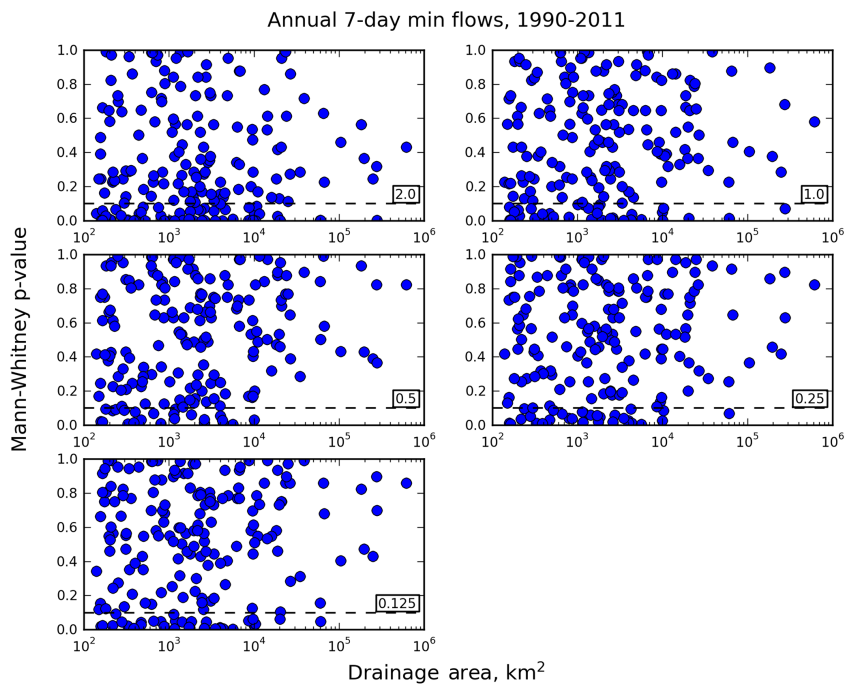

Figure 9. Similar to Fig. 8, but for the 7-day low flows at each streamflow site.

crease the number of streamflow sites with poor correspondence with observation-driven streamflows. Table 1 summarizes the results of Figs. 8 and 9, listing the number of streamflow sites for which skill is low, both for $p<0.1$ and $p<0.05$. The bias correction being performed at $0.5^{\circ}$ is revealed as an optimum, confirming the visual interpretations of Figs. 8 and 9.

Limitations of this study include the use of a single largescale forcing data set; GCMs at different native spatial resolutions may produce different results. The biases in different GCMs will also affect the performance of the bias correction, and thus would affect the outcomes. The spatial scale of the hydrological model, and its representation of sub-grid spatial variability, may also affect the results, thus different parameterizations of the SWAT model or the use of other hydrology models would affect results (Ficklin and Barnhart, 2014; Maurer et al., 2010a). Results may also be dependent on the metric used for testing correspondence, for example, examining impacts other than streamflow. Also, this study focused on biases at different scales for output from the BCSD process as it is typically applied. We did not assess the influ- 
ence of each step in the BCSD process (as shown in Fig. 1) on the biases, though this could be a fruitful avenue for future research.

\section{Conclusions}

When applying statistical downscaling methods to adapt climate model data for use in regional hydrologic impacts studies, a bias correction step is typically included. A common method for bias correction is quantile mapping, which can be performed in many different ways. One way in which applications of quantile mapping vary is in the spatial scale at which it is applied, which can range from the large scale of climate model output (generally 1 to $4^{\circ}$ latitude-longitude) down to the finest resolution of observed data. This experiment investigated the effect of the spatial scale at which precipitation (and temperature) is bias corrected (as part of a statistical downscaling approach) on the streamflow produced by a hydrologic model.

Similar to many prior studies, as a surrogate for climate model data, this experiment used reanalysis data, which is at a spatial scale of approximately $1.9^{\circ}$. A gridded observational data set of daily precipitation and temperature was used as the observational baseline, and was aggregated to spatial resolutions of $0.125,0.25,0.5,1.0$, and $2.0^{\circ}$ to be used in the bias correction step of the statistical downscaling scheme. The principal findings were that bias correction at the coarsest scale $\left(2.0^{\circ}\right)$ performed worst, and performing bias correction at scales finer than $0.5^{\circ}$ produced little additional benefit, and even degraded the correspondence between observation-driven streamflows and those driven by downscaled meteorology.

This suggests that the primary assumption inherent in quantile-mapping bias correction, namely, that the biases between modeled and observed meteorological variables for a calibration period are relatively stationary in time and can be applied to a projected period, may become less valid at spatial resolution finer than approximately $0.5^{\circ}$. This may indicate a shift in the sources of uncertainty causing the biases as spatial resolution changes. Some biases, such as those caused by inadequate topographic representation in the large-scale model, are better described at fine scales and benefit from having bias correction performed at as fine a scale as possible. Other biases, due to incorrect location of climate features at the larger scale, may be less able to be corrected at very fine spatial scales (e.g., Maraun and Widmann, 2015). For the region and data sources used in this study, the spatial resolution of $0.5^{\circ}$, or approximately a $50 \mathrm{~km}$ scale, appears to provide an optimal balance between these competing effects.

The findings of this study caution against the temptation to apply quantile-mapping bias correction at the finest possible scale, even though it provides the closest correspondence to observations for the calibration period. For independent validation periods, these findings suggest that very fine scale quantile mapping will perform no better, and possibly worse, than coarsening observations to approximately $0.5^{\circ}$, and applying bias correction at that scale.

Author contributions. E. P. Maurer designed the experiment and performed the downscaling. D. L. Ficklin conducted hydrologic modeling. W. Wang provided interpretation of results. E. P. Maurer prepared the manuscript with contributions from all co-authors.

Acknowledgements. This work was supported by NASA Earth Exchange (NEX, https://nex.nasa.gov/) at NASA Ames Research Center and the Bay Area Environmental Research Institute.

Edited by: A. Bàrdossy

\section{References}

Abatzoglou, J. T. and Brown, T. J.: A comparison of statistical downscaling methods suited for wildfire applications, Int. J. Climatol., 32, 772-780, doi:10.1002/joc.2312, 2012.

Arnold, J. G., Srinivasan, R., Muttiah, R. S., and Williams, J. R.: Large Area Hydrologic Modeling and Assessment Part I: Model Development, J. Am. Water Resour. As., 34, 73-89, doi:10.1111/j.1752-1688.1998.tb05961.x, 1998.

Bárdossy, A. and Pegram, G.: Multiscale spatial recorrelation of RCM precipitation to produce unbiased climate change scenarios over large areas and small, Water Resour. Res., 48, W09502, doi:10.1029/2011wr011524, 2012.

Barnett, T. P., Pierce, D. W., Hidalgo, H. G., Bonfils, C., Santer, B. D., Das, T., Bala, G., Wood, A. W., Nozawa, T., Mirin, A. A., Cayan, D. R., and Dettinger, M. D.: Human-Induced Changes in the Hydrology of the Western United States, Science, 319, 10801083, doi:10.1126/science.1152538, 2008.

Das, T., Maurer, E. P., Pierce, D. W., Dettinger, M. D., and Cayan, D. R.: Increases in flood magnitudes in California under warming climates, J. Hydrol., 501, 101-110, doi:10.1016/j.jhydrol.2013.07.042, 2013.

Eden, J. M., Widmann, M., Grawe, D., and Rast, S.: Skill, Correction, and Downscaling of GCM-Simulated Precipitation, J. Climate, 25, 3970-3984, doi:10.1175/jcli-d-11-00254.1, 2012.

Ehret, U., Zehe, E., Wulfmeyer, V., Warrach-Sagi, K., and Liebert, J.: HESS Opinions "Should we apply bias correction to global and regional climate model data?", Hydrol. Earth Syst. Sci., 16, 3391-3404, doi:10.5194/hess-16-3391-2012, 2012.

Ficklin, D. L. and Barnhart, B. L.: SWAT hydrologic model parameter uncertainty and its implications for hydroclimatic projections in snowmelt-dependent watersheds, J. Hydrol., 519, 2081-2090, doi:10.1016/j.jhydrol.2014.09.082, 2014.

Ficklin, D. L., Stewart, I. T., and Maurer, E. P.: Projections of 21st Century Sierra Nevada Local Hydrologic Flow Components Using an Ensemble of General Circulation Models1, J. Am. Water Resour. As., 48, 1104-1125, doi:10.1111/j.17521688.2012.00675.x, 2012.

Ficklin, D. L., Stewart, I. T., and Maurer, E. P.: Climate Change Impacts on Streamflow and Subbasin-Scale Hydrology 
in the Upper Colorado River Basin, PLoS ONE, 8, e71297, doi:10.1371/journal.pone.0071297, 2013.

Ficklin, D. L., Barnhart, B. L., Knouft, J. H., Stewart, I. T., Maurer, E. P., Letsinger, S. L., and Whittaker, G. W.: Climate change and stream temperature projections in the Columbia River basin: habitat implications of spatial variation in hydrologic drivers, Hydrol. Earth Syst. Sci., 18, 4897-4912, doi:10.5194/hess-184897-2014, 2014.

Flato, G., Marotzke, J., Abiodun, B., Braconnot, P., Chou, S. C., Collins, W., Cox, P., Driouech, F., Emori, S., Eyring, V., Forest, C., Gleckler, P., Guilyardi, E., Jakob, C., Kattsov, V., Reason, C., and Rummukainen, M.: Evaluation of Climate Models, in: Climate Change 2013: The Physical Science Basis. Contribution of Working Group I to the Fifth Assessment Report of the Intergovernmental Panel on Climate Change, edited by: Stocker, T. F., Qin, D., Plattner, G.-K., Tignor, M., Allen, S. K., Boschung, J., Nauels, A., Xia, Y., Bex, V., and Midgley, P. M., Cambridge University Press, Cambridge, United Kingdom and New York, NY, USA, 741-866, 2013.

Gudmundsson, L., Bremnes, J. B., Haugen, J. E., and EngenSkaugen, T.: Technical Note: Downscaling RCM precipitation to the station scale using statistical transformations - a comparison of methods, Hydrol. Earth Syst. Sci., 16, 3383-3390, doi:10.5194/hess-16-3383-2012, 2012.

Haan, C. T.: Statistical Methods in Hydrology, second edition, Iowa State Press, Ames, IA, USA, 496 pp., 2002.

Haerter, J. O., Eggert, B., Moseley, C., Piani, C., and Berg, P.: Statistical precipitation bias correction of gridded model data using point measurements, Geophys. Res. Lett., 42, 1919-1929, doi:10.1002/2015g1063188, 2015.

Hawkins, E. and Sutton, R.: The Potential to Narrow Uncertainty in Regional Climate Predictions, B. Am. Meteorol. Soc., 90, 10951107, doi:10.1175/2009BAMS2607.1, 2009.

Hawkins, E. and Sutton, R.: The potential to narrow uncertainty in projections of regional precipitation change, Clim. Dyn., 37, 407-418, doi:10.1007/s00382-010-0810-6, 2011.

Huth, R.: Statistical downscaling of daily temperature in Central Europe, J. Climate, 15, 1731-1742, 2002.

Hwang, S. and Graham, W. D.: Development and comparative evaluation of a stochastic analog method to downscale daily GCM precipitation, Hydrol. Earth Syst. Sci., 17, 4481-4502, doi:10.5194/hess-17-4481-2013, 2013.

Kalnay, E., Kanamitsu, M., Kistler, R., Collins, W., Deaven, D., Gandin, L., Iredell, M., Saha, S., White, G., Woollen, J., Zhu, Y., Leetmaa, A., and Reynolds, B.: The NCEP/NCAR 40-year reanalysis project, B. Am. Meteorol. Soc., 77, 437-472, 1996.

Lafon, T., Dadson, S., Buys, G., and Prudhomme, C.: Bias correction of daily precipitation simulated by a regional climate model: a comparison of methods, Int. J. Climatol., 1-15, doi:10.1002/joc.3518, 2012.

Li, H., Sheffield, J., and Wood, E. F.: Bias correction of monthly precipitation and temperature fields from Intergovernmental Panel on Climate Change AR4 models using equidistant quantile matching, J. Geophys. Res., 115, D10101, doi:10.1029/2009jd012882, 2010.

Li, J., Sharma, A., Johnson, F., and Evans, J.: Evaluating the effect of climate change on areal reduction factors using regional climate model projections, J. Hydrol., 528, 419-434, doi:10.1016/j.jhydrol.2015.06.067, 2015.
Livneh, B., Rosenberg, E. A., Lin, C., Nijssen, B., Mishra, V., Andreadis, K. M., Maurer, E. P., and Lettenmaier, D. P.: A LongTerm Hydrologically Based Dataset of Land Surface Fluxes and States for the Conterminous United States: Update and Extensions, J. Climate, 26, 9384-9392, doi:10.1175/jcli-d-12-00508.1, 2013.

Maraun, D.: Nonstationarities of regional climate model biases in European seasonal mean temperature and precipitation sums, Geophys. Res. Lett., 39, L06706, doi:10.1029/2012g1051210, 2012.

Maraun, D.: Bias Correction, Quantile Mapping, and Downscaling: Revisiting the Inflation Issue, J. Climate, 26, 2137-2143, doi:10.1175/jcli-d-12-00821.1, 2013.

Maraun, D.: Reply to "Comment on 'Bias Correction, Quantile Mapping, and Downscaling: Revisiting the Inflation Issue"', J. Climate, 27, 1821-1825, doi:10.1175/jcli-d-13-00307.1, 2014.

Maraun, D. and Widmann, M.: The representation of location by a regional climate model in complex terrain, Hydrol. Earth Syst. Sci., 19, 3449-3456, doi:10.5194/hess-19-3449-2015, 2015.

Maraun, D., Wetterhall, F., Ireson, A. M., Chandler, R. E., Kendon, E. J., Widmann, M., Brienen, S., Rust, H. W., Sauter, T., Themeß1, M., Venema, V. K. C., Chun, K. P., Goodess, C. M., Jones, R. G., Onof, C., Vrac, M., and Thiele-Eich, I.: Precipitation downscaling under climate change: Recent developments to bridge the gap between dynamical models and the end user Rev. Geophys., 48, RG3003, doi:10.1029/2009rg000314, 2010.

Maurer, E. P., O’Donnell, G. M., Lettenmaier, D. P., and Roads, J. O.: Evaluation of the land surface water budget in NCEP/NCAR and NCEP/DOE reanalyses using an off-line hydrologic model, J. Geophys Res., 106, 17841-17862, 2001.

Maurer, E. P., Brekke, L. D., Pruitt, T., and Duffy, P. B.: Fine-resolution climate change projections enhance regional climate change impact studies, Eos Trans. AGU, 88, 504, doi:10.1029/2007EO470006, 2007.

Maurer, E. P., Brekke, L. D., and Pruitt, T.: Contrasting Lumped and Distributed Hydrology Models for Estimating Climate Change Impacts on California Watersheds1, J. Am. Water Resour. As., 46, 1024-1035, doi:10.1111/j.1752-1688.2010.00473.x, 2010a.

Maurer, E. P., Hidalgo, H. G., Das, T., Dettinger, M. D., and Cayan, D. R.: The utility of daily large-scale climate data in the assessment of climate change impacts on daily streamflow in California, Hydrol. Earth Syst. Sci., 14, 1125-1138, doi:10.5194/hess14-1125-2010, 2010b.

Maurer, E. P., Das, T., and Cayan, D. R.: Errors in climate model daily precipitation and temperature output: time invariance and implications for bias correction, Hydrol. Earth Syst. Sci., 17, 2147-2159, doi:10.5194/hess-17-2147-2013, 2013.

Maurer, E. P., Brekke, L., Pruitt, T., Thrasher, B., Long, J., Duffy, P., Dettinger, M., Cayan, D., and Arnold, J.: An enhanced archive facilitating climate impacts and adaptation analysis, B. Am. Meteorol. Soc., doi:10.1175/bams-d-13-00126.1, 2014.

Meehl, G. A., Covey, C., Delworth, T., Latif, M., McAvaney, B., Mitchell, J. F. B., Stouffer, R. J., and Taylor, K. E.: The WCRP CMIP3 multimodel dataset: A new era in climate change research, B. Am. Meteorol. Soc., 88, 1383-1394, 2007.

Mehrotra, R. and Sharma, A.: An improved standardization procedure to remove systematic low frequency variability biases in GCM simulations, Water Resour. Res., 48, W12601, doi:10.1029/2012WR012446, 2012. 
Mehrotra, R. and Sharma, A.: Correcting for systematic biases in multiple raw GCM variables across a range of timescales, J. Hydrol., 520, 214-223, doi:10.1016/j.jhydrol.2014.11.037, 2015.

Panofsky, H. A. and Brier, G. W.: Some Applications of Statistics to Meteorology, The Pennsylvania State University, University Park, PA, USA, 224 pp., 1968.

Piani, C., Haerter, J., and Coppola, E.: Statistical bias correction for daily precipitation in regional climate models over Europe, Theor. Appl. Climatol., 99, 187-192, doi:10.1007/s00704-0090134-9, 2010.

Pierce, D. W., Cayan, D. R., Maurer, E. P., Abatzoglou, J. T., and Hegewisch, K. C.: Improved Bias Correction Techniques for Hydrological Simulations of Climate Change, J. Hydrometeorology, 16, 2421-2442, doi:10.1175/JHM-D-14-0236.1, 2015.

Reichler, T. and Kim, J.: How Well Do Coupled Models Simulate Today's Climate?, B. Am. Meteorol. Soc., 89, 303-311, doi:10.1175/BAMS-89-3-303, 2008.

Schmidli, J., Frei, C., and Vidale, P. L.: Downscaling from GCM precipitation: A benchmark for dynamical and statistical downscaling, Int. J. Climatol., 26, 679-689, 2006.

Sheffield, J., Barrett, A., Colle, B., Fernando, D. N., Fu, R., Geil, K. L., Hu, Q., Kinter, J., Kumar, S., Langenbrunner, B., Lombardo, K., Long, L. N., Maloney, E., Mariotti, A., Meyerson, J. E., Mo, K. C., Neelin, J. D., Nigam, S., Pan, Z., Ren, T., RuizBarradas, A., Serra, Y. L., Seth, A., Thibeault, J. M., Stroeve, J. C., Yang, Z., and Yin, L.: North American Climate in CMIP5 Experiments. Part I: Evaluation of Historical Simulations of Continental and Regional Climatology, J. Climate, 26, 9209-9245, doi:10.1175/jcli-d-12-00592.1, 2013a.

Sheffield, J., Camargo, S. J., Fu, R., Hu, Q., Jiang, X., Johnson, N., Karnauskas, K. B., Kim, S. T., Kinter, J., Kumar, S., Langenbrunner, B., Maloney, E., Mariotti, A., Meyerson, J. E., Neelin, J. D., Nigam, S., Pan, Z., Ruiz-Barradas, A., Seager, R., Serra, Y. L., Sun, D.-Z., Wang C., Xie, S.-P., Yu, J.-Y., Zhang, T., and Zhao, M.: North American climate in CMIP5 experiments, Part II: Evaluation of historical simulations of intraseasonal to decadal variability, J. Climate, 26, 9247-9290, doi:10.1175/JCLI-D-1200593.1, 2013b.

Snover, A. K., Hamlet, A. F., and Lettenmaier, D. P.: ClimateChange Scenarios for Water Planning Studies: Pilot Applications in the Pacific Northwest, B. Am. Meteorol. Soc., 84, 1513-1518, doi:10.1175/BAMS-84-11-1513, 2003.

Taylor, K. E., Stouffer, R. J., and Meehl, G. A.: An Overview of CMIP5 and the experiment design, B. Am. Meteorol. Soc., 93, 485-498, doi:10.1175/BAMS-D-11-00094.1, 2012.

Teutschbein, C. and Seibert, J.: Is bias correction of regional climate model (RCM) simulations possible for nonstationary conditions?, Hydrol. Earth Syst. Sci., 17, 5061-5077, doi:10.5194/hess-17-5061-2013, 2013.
Themeß1, M., Gobiet, A., and Leuprecht, A.: Empirical-statistical downscaling and error correction of daily precipitation from regional climate models, Int. J. Climatol., 31, 1530-1544, doi:10.1002/joc.2168, 2011.

Thrasher, B., Maurer, E. P., McKellar, C., and Duffy, P. B.: Technical Note: Bias correcting climate model simulated daily temperature extremes with quantile mapping, Hydrol. Earth Syst. Sci., 16, 3309-3314, doi:10.5194/hess-16-3309-2012, 2012.

Tian, D., Martinez, C. J., and Graham, W. D.: Seasonal Prediction of Regional Reference Evapotranspiration Based on Climate Forecast System Version 2, J. Hydrometeorol., 15, 1166-1188, doi:10.1175/jhm-d-13-087.1, 2014.

Tryhorn, L. and DeGaetano, A.: A comparison of techniques for downscaling extreme precipitation over the Northeastern United States, Int. J. Climatol., 31, 1975-1989, doi:10.1002/joc.2208, 2011.

Vrac, M., Stein, M., and Hayhoe, K.: Statistical downscaling of precipitation through nonhomogeneous stochastic weather typing, Clim. Res., 34, 169-184, doi:10.3354/cr00696, 2007.

Watterson, I. G., Bathols, J., and Heady, C.: What Influences the Skill of Climate Models over the Continents?, B. Am. Meteorol. Soc., 95, 689-700, doi:10.1175/bams-d-12-00136.1, 2014.

Widmann, M. and Bretherton, C. S.: Validation of mesoscale precipitation in the NCEP reanalysis using a new grid-cell precipitation dataset for the Northwestern United States, J. Climate, 13, 1936-1950, 2000.

Wilby, R. L., Hay, L. E., Gutowski, W. J., Arritt, R. W., Takle, E. S., Pan, Z., Leavesley, G. H., and Clark, M. P.: Hydrological responses to dynamically and statistically downscaled climate model output, Geophys. Res. Lett., 27, 1199-1202, 2000.

WMO: Manual on Low-flow Estimation and Prediction, Operational Hydrology Report No. 50, World Meteorological Organization, Geneva, Switzerland, 138, 2009.

Wood, A. W., Leung, L. R., Sridhar, V., and Lettenmaier, D. P.: Hydrologic implications of dynamical and statistical approaches to downscaling climate model outputs, Climatic Change, 62, 189216, 2004.

Yuan, X. and Wood, E. F.: Downscaling precipitation or bias-correcting streamflow? Some implications for coupled general circulation model (CGCM)-based ensemble seasonal hydrologic forecast, Water Resour. Res., 48, W12519, doi:10.1029/2012WR012256, 2012.

Zhang, F. and Georgakakos, A.: Joint variable spatial downscaling, Climatic Change, 111, 945-972, doi:10.1007/s10584-011-01679, 2012. 